\title{
Exclusive Breastfeeding Behavior Model in Rural Central Java, Indonesia: The Application of Theory of Planned Behavior
}

\author{
Endang S. Sulaeman ${ }^{1}$, Bhisma Murti ${ }^{1}$, Haris Setyawan ${ }^{2}$ \& Seviana Rinawati ${ }^{2}$ \\ ${ }^{1}$ Masters Program in Public Health, Universitas Sebelas Maret, Indonesia \\ ${ }^{2}$ Industrial Hygiene, Occupational Health and Safety Program, F Building, Faculty of Medicine, Universitas \\ Sebelas Maret, Indonesia \\ Correspondence: Endang S. Sulaeman, Masters Program in Public Health, UniversitasSebelasMaret, Indonesia. \\ Tel: 62-817-774-236. E-mail: sutisnaend_dr@yahoo.com
}

Received: July 8, 2018 Accepted: August 24, 2018 Online Published: September 3, 2018

doi:10.5539/gjhs.v10n10p35 URL: https://doi.org/10.5539/gjhs.v10n10p35

\begin{abstract}
Exclusive breastfeeding's coverage is low in Indonesia, because attitude, subjective norm and perceived behavioral control fail affecting exclusive breastfeeding intention and behavior. Objectives of research were to formulate exclusive breastfeeding behavior and to explore the relationship of attitude, subjective norm, and behavioral control to exclusive breastfeeding intention and behavior. Mixed method was conducted in rural areas of Karanganyar Regency, Indonesia. Firstly, this was a survey research with attitude, subjective norm, and perceived behavioral control being independent variables. Dependent variables were exclusive breastfeeding intention and behavior. Population of research consisted of 873 lactating mothers. Sampling technique employed was multistage random sampling, with 126 lactating mothers being the sample. Data was collected using questionnaire, data analysis using path analysis. Secondly, case study was conducted through in-depth interview, focus group discussion (FGD), document review, and observation. In-depth interview and FGD was conducted with 49 participants: 30 lactating mothers and 19 health workers. Data analysis was conducted content analysis. The result showed that attitude, affective norm, and perceived behavioral control correlated with exclusive breastfeeding intention $(\beta=0.09 ; \mathrm{p}=0.084 ; \beta=0.09 ; \mathrm{p}=0.027 ; \beta=0.51 ; \mathrm{p}<0.001$, respectively). Perceived behavioral control and intention correlated with exclusive breastfeeding behavior $(\beta=0.08 ; p=0.059 ; \beta=0.09 ; p$ $=0.068$, respectively). Exclusive breastfeeding behavior model included attitude, subjective norm, perceived behavioral control, and exclusive breastfeeding behavior. Attitude, subjective norm, and perceived behavioral control collectively correlated with intention; intention and perceived behavioral perception were direct determinants of exclusive breastfeeding behavior.
\end{abstract}

Keywords: attitude, subjective norm, perceived behavioral control, intention and behavior

\section{Introduction}

The benefit of breastfeeding for health has been published widely. Breastfeeding clearly benefits the child health in short term, particularly protection against infectious disease-induced morbidity and mortality (Horta et al., 2007). Infants breastfed exclusively for 6 six months develop less gastrointestinal infection-induced morbidity than those fed with formula milk in at 3 or 4 month-age, and do not have growth deficit in both developing and developed countries (Kramer \& Kakuma, 2002). On the other hand, there are some controversies about long-term consequence of breastfeeding. Some studies reported that infants breastfed exclusively have higher school achievement and performance in intelligence test, low blood pressure, low total cholesterol level, and low overweight and obesity prevalence (Horta et al., 2007). To optimize infant growth and development, WHO and United Nations' Children Fund (2003) recommend globally the optimization the exclusive breastfeeding up to six month and continued with lactating up to 2 years or more. However, in most countries the proportion of mother breastfeeding their infant exclusively up to six months is still low (Imdad et al., 2011).

Despite some attempts taken to deal with the challenge in overcoming malnutrition and early death among Indonesian rural children through many health and nutrition programs, the exclusive breastfeeding level has not been achieved yet. High infant mortality rate, low nutrition status and low exclusive breastfeeding rate in rural areas exacerbate the situation. Exclusive breastfeeding prevalence in Indonesia is still low, 29.5\% (Republic of Indonesia's Health Ministry, 2017). Exclusive breastfeeding is defined as feeding the infant with breast milk only 
(including the breast milk expressed or from other lactating mother) and with nothing but rehydrated oral saline, drugs and vitamin, and mineral (WHO, 2002). The improved exclusive breastfeeding rate can help encourage the progress toward other global nutrition target (stunting, anemia in reproductive-age women, low birth weight, overweight and lean children), and be the most important instrument of policy maker to improve health and economy. Policy maker should consider action priority, in the attempt of improving exclusive breastfeeding rate in the first six-month life at least up to $50 \%$ (WHO, 2014).

In last decades, theory of planned behavior (TPB) has been a framework of explaining and predicting behavior (Fishbein \& Ajzen, 2010). TPB is a theory focusing on cognitive factors affecting individual's behavior. This theory states that the main driver of behavior is intention to perform such behavior, including the following constructs: behavior, intention, attitude, subjective norm, and perceived behavioral control. Behavior is the way an individual acts; individual's way and reaction in different situation; individual's actual behavior when decision in an action is voluntary in nature and under individual's control; behavior is an individual's response observed in certain situation in relation to the target given; behavior is function of intention appropriate to performing behavior and correlates with individual's belief in their ability of performing behavior (Ajzen, 2005).

Attitude is an individual's belief in the consequence of behavior performed; attitude is the extent to which an individual has either advantageous or disadvantageous comprehensive evaluation on behavior; attitude is utility or non-utility number of behavior. Two factors lead to attitude creation, i.e. behavioral belief and result evaluation (Ajzen, 2005). Meanwhile, subjective norm is individual's perceived social pressure from others significant in his/her environment to do or not to do considered behavior; subjective norm consists of injunctive and descriptive ones. Injunctive norm refers to perception that others significant will support or oppose them to perform behavior, while descriptive norm is perception that others significant have or have not performed the behavior (Ismail et al., 2016) as an impulse to follow others' perception on behavior to perform. Two factors lead to subjective norm creation: normative belief and motivation of compliance.

Perceived behavioral control is an individual's perception on the extent to which he/she perform or does not perform a behavior under voluntary control; on easiness or difficulty in performing a behavior; on their control over behavior and confidence to control behavior (Ajzen, 2012). Perceived behavioral control is defined as self-efficacy, the individual's experience with performing or not performing a behavior, the individual has facility or time to perform behavior, and then individual estimates his/her self-ability whether or not he/she has or does not have ability of performing behavior (Ajzen, 2005). TPB admits that intention and perceived behavioral control is direct determinant of behavior (Fishbein \& Ajzen, 2010). Two factors lead to creating perceived behavioral control: control belief and perceived power. Mother having self-confidence in lactating will be ready in dealing with lactating problem. However, mothers' self-confidence also relates to some dimensions, among others: mothers' health status, occupation, knowledge on lactating, culture, education, and career (Swanson \& Power, 2005).

Key factor of TPB is individual's intention to perform a behavior; intention as the main driver to perform behavior. This theory argues that behavior is determined directly by intention to perform behavior and without behavior, a behavior will unlikely occur. Thus, intention is the main focus of TPB as assumed to be direct determinant of performing or not performing a behavior. Intention is the function of variable underlying motivation (i.e. attitude to behavior, subjective norm, and perceived behavioral control). Motivation encourages an individual to perform a behavior. Intention serves as individual's perception on certain behavior performance as well (Ajzen, 2005). Intention is a certainty level of behavioral practice; serves as main determinant and predictor of behavior; is direct antecedent/precursor of behavior. This theory states that intention is determined by three constructs: individual's attitude on behavior, subjective norm within society concerning behavior and perceived behavioral control to practice behavior (Fishbein \& Ajzen, 2010).

This theory has been used by many researchers concerning breastfeeding intention, finding that the three constructs - attitude, subjective norm, and perceived behavioral control - have significant effect on breastfeeding intention (Al-Akour etal., 2010; Swanson \& Power, 2005; Kavanagh et al., 2012). TPB has been used widely to predict breastfeeding practice in cross-cultural order (Dodgson et al., 2003). The author identified first the breastfeeding intention as main determinant of breastfeeding behavior (Forster et al., 2006; Shi et al., 2008). TPB is an appropriate framework to identify the factors related to exclusive breastfeeding behavior among breastfeeding mother. Generally, studies on breastfeeding intention have been conducted on pregnant women and these have been conducted inadequately on lactating women in rural areas. For that reason, the objectives of research are to formulate exclusive breastfeeding behavior model and to explore the relationship of attitude, subjective norm, and perceived behavioral control to exclusive breastfeeding intention and behavior in lactating women in rural areas of Karanganyar Regency, Central Java, Indonesia. 


\section{Method}

\subsection{Study Design and Setting}

This was a mixed method study consisting of a cross-sectional quantitative study and a qualitative study. The study was carried out in rural areas, Karanganyar Regency, Central Java, Indonesia, from April to August 2016. This study site was selected due its low level of exclusive breastfeeding.

\subsection{Population and Sample}

The target population of the present study was lactating mothers who had infants aged 6 to 12 months. The accessible population was 873 lactating mothers who had infants aged 6 to 12 months and lived in rural areas, Karanganyar Regency, Central Java. A sample of 135 lactating mothers was taken from 14 out of 177 villages by multistage random sampling. A total of 49 key informants were selected purposively for the qualitative component of this study, comprising 30 lactating mothers and 19 stakeholders of exclusive breastfeeding program including personnel from community health centers and Regency Health Office.

\subsection{Study Variables}

The dependent variables were exclusive breastfeeding and its intention. The independent variables included attitude towards exclusive breastfeeding, subjective norm, and perceived behavioral control. The socio-demographic characteristics of the sample included infant age, maternal age, parity, education, and occupation.

\subsection{Data Collection}

Data was collected through face-to-face interview using a set of structured questionnaire. Data included attitude, subjective norm, perceived behavioral control, exclusive breast feeding intention, and behavior. These variables were measured by a pre-tested questionnaire with 4 level Likert scale options with the highest score (4) given to strongly agree and the lowest score (1) to strongly disagree. Reliability analysis of the questionnaire resulted in Cronbach alpha of 0.81 for knowledge, 0.88 for attitude, 0.81 for subjective norm, 0.83 for perceived behavioral control, 0.82 for intention, and 0.78 for behavior, all of which exceeded 0.70 threshold.

The qualitative data of the present study were collected by in-depth interview, Focus Group Discussion (FGD), document review, and observation.

\subsection{Data Analysis}

The quantitative data were analyzed by path analysis model run on IBM SPSS AMOS 22. It proceeded through the following steps (1) Model specification; (2) Model identification; (3) Model fit; (4) Estimation; and (5) Model re-specification (if necessary).

The qualitative data analysis involved content analysis, encompassing data reduction, data display, and conclusion. Information was formulated and interpreted. Interpretive analysis was conducted to reveal the best learning practice to understand the case (Miles \& Huberman, 1994).

\subsection{Ethics Approval}

This study received research ethics approval from the Health Research Ethics Committee of Dr. Moewardi Hospital/ School of Medicine, UniversitasSebelasMaret, Surakarta, Central Java, Indonesia. Information about objective of the study, procedures, potential risks, and benefits, was given to mothers before enrolment in the study. Participation in the survey was voluntary and participants' full right to refuse participation was explained.

\section{Results}

The secondary data showed that the level of exclusive breastfeeding in Karanganyar Regency, Central Java in 2013 was low at $14.93 \%$, increased to $25.12 \%$ in 2014 , and declined to $18.2 \%$ by 2015 (Karanganyar Regency Health Office, 2017). The study area was rural, consisting of 162 villages with a population density of 1,114 people $/ \mathrm{km}^{2}$. About 173,182 out of 870,679 population $(19.89 \%$ ) had no schooling. Literacy rate was $90.32 \%$ and $12.45 \%$ of the population lived below the poverty line. The study site was agrarian, most of which was used for farming. Around $22.39 \%$ of its population was farmers (Karanganyar Regency Government, 2017).

\subsection{Quantitative Study}

\subsubsection{Sample Characteristics}

Table 1 showed that half of the sample was between 26 and 35 years of age. Most of the infants were between 6 and 9 months of age. The majority (about $80 \%$ ) of mothers under study completed high school. 
Table 1. Demographic characteristics of the study sample $(n=135)$

\begin{tabular}{lcc}
\hline Characteristics & $\mathrm{n}$ & $\%$ \\
\hline Age of mothers (years) & 32 & 23.7 \\
$17-25$ & 77 & 57.05 \\
$26-35$ & 25 & 18.5 \\
$36-45$ & 1 & 0.75 \\
$46-55$ & & \\
\hline Age of infant (months) & 98 & 72.59 \\
$6-9$ & 37 & 27.41 \\
$10-12$ & & \\
\hline Mother's education level & 1 & 0.75 \\
Not attending school & 11 & 8.15 \\
Graduated from Elementary School & 51 & 37.77 \\
Graduated from Junior High School & 55 & 40.74 \\
Graduated from Senior High School & 17 & 12.59 \\
Graduated from University & & \\
\hline Mother's employment status: & 58 & 42.96 \\
Employed & 77 & 57.04 \\
House wife & & \\
\hline Parity & 126 & 63.33 \\
1 -3 & 9 & 6.67 \\
Above 3 & & \\
\hline
\end{tabular}

\subsubsection{Univariate Analysis}

Table 3 shows that study participants with the following characteristics: mothers aged 26-35 years (25.92\%) with Junior High School education (20.74\%) and housewives (30.37\%), have strong breastfeeding intention. Most participants have good knowledge and strong exclusive breastfeeding intention (54-70\%), positive attitude and strong exclusive breastfeeding intention (47.41\%), high subjective norm and strong exclusive breastfeeding intention (49.63\%), good perceived behavioral control and strong exclusive breastfeeding intention (53.33\%). There was a significant relationship between exogenous variable (mother age, education level, occupational status, knowledge, attitude, and perceived behavioral control) and endogenous variable (exclusive breastfeeding intention). 
Table 3. Demographic characteristics, knowledge, attitude, subjective norm, and perceived behavioral control correlate to exclusive breastfeeding intention

\begin{tabular}{|c|c|c|c|c|c|}
\hline \multirow{3}{*}{ Variables } & \multicolumn{5}{|c|}{ Exclusive breastfeeding intention } \\
\hline & \multicolumn{2}{|l|}{ Strong } & \multicolumn{2}{|c|}{ Weak } & \multirow[t]{2}{*}{$\mathrm{p}$} \\
\hline & $\mathrm{n}$ & $\%$ & $\mathrm{n}$ & $\%$ & \\
\hline Age of mother (year) & & & & & 0.031 \\
\hline $17-25$ & 15 & 11.11 & 17 & 12.59 & \\
\hline $26-35$ & 35 & 25.93 & 42 & 31.11 & \\
\hline $36-45$ & 15 & 11.11 & 10 & 7.41 & \\
\hline $46-55$ & 1 & 0.74 & 0 & .00 & \\
\hline Education Level & & & & & 0.032 \\
\hline Not attending school & 0 & .00 & 1 & 0.74 & \\
\hline Graduated from Elementary School & 7 & 5.19 & 4 & 2.96 & \\
\hline Graduated from Junior High School & 28 & 20.74 & 23 & 17.03 & \\
\hline Graduated from Senior High School & 24 & 17.78 & 31 & 22.96 & \\
\hline Graduated from University & 7 & 5.19 & 10 & 7.41 & \\
\hline Mother's employment status & & & & & 0.001 \\
\hline Employed & 35 & 25.92 & 23 & 17.04 & \\
\hline Housewife & 41 & 30.37 & 36 & 26.67 & \\
\hline Knowledge & & & & & 0.045 \\
\hline Good & 73 & 54.07 & 10 & 7.41 & \\
\hline Poor & 15 & 11.11 & 37 & 27.41 & \\
\hline Attitude & & & & & 0.072 \\
\hline Positive & 64 & 47.41 & 8 & 5.93 & \\
\hline Negative & 7 & 5.18 & 56 & 41.48 & \\
\hline Subjective norm & & & & & 0.006 \\
\hline High & 67 & 49.63 & 11 & 8.15 & \\
\hline Low & 8 & 5.92 & 49 & 36.30 & \\
\hline Perceived behavioral control & & & & & 0.001 \\
\hline Good & 72 & 53.33 & 11 & 8.15 & \\
\hline Poor & 7 & 5.19 & 45 & 33.33 & \\
\hline
\end{tabular}

\subsubsection{Bivariate Analysis}

The summary of relationship between exogenous and endogenous variables of exclusive breastfeeding behavior is shown in Table 4. 
Table 4. Summary of relationship between exogenous and endogenous variables (exclusive breastfeeding intention and behavior) in lactating mothers in rural areas of Karanganyar Regency, Central Java, Indonesia

\begin{tabular}{|c|c|c|c|c|}
\hline \multirow{3}{*}{ Exogenous variables } & \multirow{2}{*}{\multicolumn{2}{|c|}{$\begin{array}{l}\text { Endogenous: } \\
\text { Exclusive breastfeeding intention }\end{array}$}} & \multirow{2}{*}{\multicolumn{2}{|c|}{$\begin{array}{l}\text { Endogenous: } \\
\text { Exclusive breastfeeding Behavior }\end{array}$}} \\
\hline & & & & \\
\hline & B & $\mathbf{p}$ & $\mathbf{B}$ & $\mathbf{p}$ \\
\hline Attitudes & 2.80 & 0.084 & - & - \\
\hline Subjective norm & 0.09 & 0.027 & - & - \\
\hline Perception of control behavior & 0.51 & 0.001 & 0.08 & 0.059 \\
\hline Exclusive breastfeeding intention & - & - & 0.09 & 0.068 \\
\hline
\end{tabular}

Note. ß (standardized path coefficient/regression coefficient);

$\mathrm{p}=$ significance.

Table 4 shows that exogenous variables affecting endogenous variable (exclusive breastfeeding intention) significantly are attitude, subjective norm, and perceived control behavior. Exogenous variables affecting significantly the endogenous variable (exclusive breastfeeding behavior) perceived behavioral control and exclusive breastfeeding intention.

\subsubsection{Multivariate Analysis}

Figure 1 shows that the result of path analysis is as follows: (1) there is a direct and significant relationship of attitude, subjective norm, and perceived behavioral control to exclusive breastfeeding intention with scores of 2.80 , 0.09 , and 0.51 , respectively; (2) there is a direct and significant relationship of exclusive breastfeeding intention and perceived behavioral control to exclusive breastfeeding behavior with scores of 0.9 , and 0.08 , respectively.

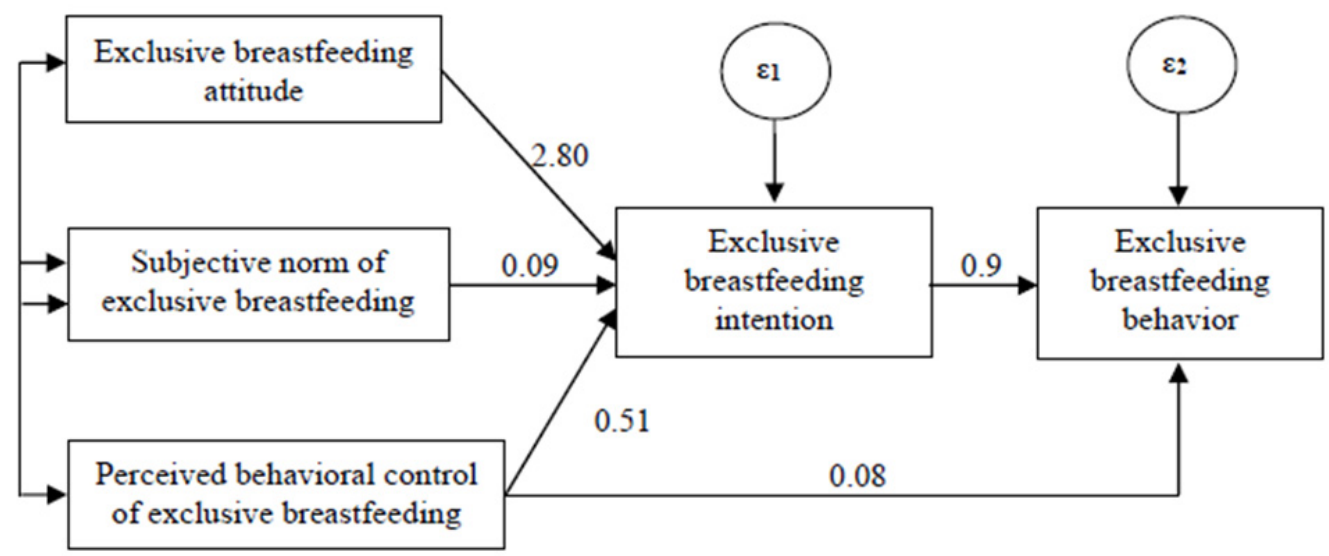

Figure 1. Result of path analysis on exclusive breastfeeding behavior

Considering the result of path analysis, the following conclusions can be drawn: (1) There is a direct and significant relationship between attitude and exclusive breastfeeding intention. Each 1 unit increase in attitude will increase exclusive breastfeeding intention by 2.80 point $(\beta=2.80 ; p=0.084)$. (2) There is a direct and significant relationship between subjective norm and exclusive breastfeeding intention. Each 1 unit increase in subjective norm will increase exclusive breastfeeding intention by 0.09 point $(\beta=0.09 ; p=0.027)$. (3) There is a direct and significant relationship between perceived behavioral control and exclusive breastfeeding intention. Each 1 unit increase in perceived behavioral control will increase exclusive breastfeeding intention by 0.51 point $(\beta=0.51 ; p$ $<0.001)$. (4) There is a direct and significant relationship between exclusive breastfeeding intention and exclusive breastfeeding behavior. Each 1 unit increase in exclusive breastfeeding intention will increase exclusive breastfeeding behavior by 0.09 point $(ß=0.09 ; \mathrm{p}=0.068)$. (5) There is a direct and significant relationship between perceived behavioral control and exclusive breastfeeding behavior. Each 1 unit increase in perceived behavioral control will increase exclusive breastfeeding behavior by 0.08 point $(ß=0.09 ; \mathrm{p}=0.059)$. 


\subsection{Qualitative study}

\subsubsection{Informants}

Table 2 shows that half of mother informants were 30-39 years of age, 56.7\% completed Senior High School, and $80 \%$ worked. Nearly half of the health workers aged 30-39 years, mostly completed higher education, and half had 10 year-tenure.

Table 2. Socio-demographic characteristics of informant

\begin{tabular}{|c|c|c|c|c|c|}
\hline \multicolumn{3}{|c|}{ Lactating mother informants $(\mathrm{n}=30)$} & \multicolumn{3}{|c|}{ Health Worker Informant $(\mathrm{n}=19)$} \\
\hline Characteristics & Number & Percentage & Characteristics & Number & Percentage \\
\hline Age & & & Age & & \\
\hline 20-29 years & 12 & $40 \%$ & 20-29 years & 3 & $15.79 \%$ \\
\hline 30-39 years & 17 & $56.7 \%$ & 30-39 years & 9 & $47.39 \%$ \\
\hline$>40$ years & 1 & $3.3 \%$ & $>40$ years & 7 & $36.84 \%$ \\
\hline Education & & & Education & & \\
\hline Elementary School & 1 & $3.3 \%$ & Elementary School & - & - \\
\hline Junior High School & 6 & $20 \%$ & Junior High School & - & - \\
\hline Senior High School & 17 & $56.7 \%$ & Senior High School & 2 & $10.52 \%$ \\
\hline College or Higher Education & 6 & $20 \%$ & College or Higher Education & 17 & $89.48 \%$ \\
\hline Occupation & & & Tenure & & \\
\hline Housewives & 6 & $20 \%$ & $<10$ years & 11 & $57.89 \%$ \\
\hline Working & 24 & $80 \%$ & $>10$ years & 8 & $42.11 \%$ \\
\hline
\end{tabular}

\subsubsection{Case Study Research}

\subsubsection{Result of In-Depth Interview}

The result of in-depth interview with lactating mothers and stakeholders of exclusive breastfeeding program in Public Health Center and Health Service of Karanganyar Regency is presented below.

\section{The relationship between lactating mothers' attitude and exclusive breastfeeding intention}

The following is the result of in-depth interview with some informants:

"I think exclusive breastfeeding is beneficial to me. Exclusive breastfeeding is available any time. I breastfeeds my baby once in an hour" (lactating mother, 38 years with 2-month baby).

"Lactating mothers' attitude to exclusive breastfeeding relates to exclusive breastfeeding intention. When lactating mother have positive attitude to exclusive breastfeeding, she will breastfeed her baby exclusively" (Female, Coordinator Midwife of Public Health Center).

"Lactating mothers' attitude relates to their intention, and their attitude defines the exclusive breastfeeding decision to be taken. Lactating mothers' exclusive breastfeeding intention will motivate the implementation of exclusive breastfeeding. Exclusive breastfeeding intention should be supported by husband, closest family, and health workers, so that intention will be implemented in the behavior" (Male, physician, Chairman of Public Health Center).

"Mother having positive attitude to exclusive breastfeeding will have exclusive breastfeeding intention" (Female, Nutrition Specialist of Regency's Health Service).

From the information above, it can be interpreted that lactating mothers' attitude dimension shows the extent to which a mother has favorable and unfavorable evaluation on exclusive breastfeeding behavior as lactating mothers' belief in the consequence of exclusive breastfeeding behavior. Lactating mothers' attitude to exclusive breastfeeding relates to exclusive breastfeeding intention, and attitude will define the decision to be taken. If lactating mothers have negative perception, for example she assumes that her breast milk will be inadequate, she will not breastfeed her baby exclusively. Lactating mothers' exclusive breastfeeding intention will motivate them 
to breastfeed their baby exclusively. Exclusive breastfeeding intention should be supported by husband, closest family, and health workers so that exclusive breastfeeding intention will be implemented in exclusive breastfeeding behavior.

3.2.2.2 The Relationship Between Subjective Norm of Exclusive Breastfeeding and Exclusive Breastfeeding Intention

The following is the result of in-depth interview with several informants:

"My husband and mother in law support me to breastfeed my baby exclusively, so that I always do so" (Lactating mothers, 27 years, with 4-month baby).

"Husband, mother in law, relative, neighbor, and health workers' pressure to breastfeed exclusively encourages lactating mothers to do so" (Female, Coordinator midwife of Public Health Center).

"Family's particularly husband, mother in law, and family members' motivation, determines exclusive breading behavior" (Male, physician, Chairman of Public Health Center).

"Some mothers assume that their breast milk is inadequate to be given exclusively for 6 months, thereby needing supplement food such as banana. Another case also occurs in a hospital in which when a mother wants to breastfeed her baby, her breast milk cannot be produced, so that she gives her baby formula milk" (Male, physician, stakeholder of Regency's Health Service).

"My relatives, neighbors, and friends have breastfeed their babies exclusively, and so do I" (Lactating mothers, 23 years, 3-month baby).

From the information above, it can be interpreted that subjective norm is an individual's perception on social pressure from others significant in their environment to perform exclusive breastfeeding behavior; perception that those important people have performed exclusive breastfeeding behavior; lactating mothers' perception on support and resource availability, or social pressure existing in their environment to perform exclusive breeding behavior and their motivation to follow others' perception on exclusive breastfeeding behavior. When lactating mothers get support from environment (e.g. husband, mother in law, family, neighbor, friend, and health workers), they will breastfeed their babies exclusively. Furthermore, when they consider that exclusive breastfeeding is their private right rather than determined by others surrounding, they will ignore others' perception about exclusive breastfeeding behavior.

3.2.2.3 The Relationship Between Perceived Control Over Exclusive Breastfeeding and Exclusive Breastfeeding Intention

"I believe that I can breastfeed my baby exclusively because I have done so since my first child; so for my second child, I will do so" (Lactating mother, 31 year, 2-month baby).

"I have ever breastfeed my baby exclusively, I have time to do so and my breast milk is adequate; therefore I have exclusive breastfeeding intention" (Lactating mothers, 28 years, with 3-month baby).

"If lactating mothers have behavioral control and trust in controlling exclusive breastfeeding behavior, they generally have exclusive breastfeeding intention and behavior" (Female, stakeholder of Regency's Health Service).

"Exclusive breastfeeding intention is supported with the easiness in exclusive breastfeeding. Breast milk can be produced easily and adequately, exclusive breastfeeding room and supporting family environment are available" (Female, Physician, Chairman of Public Health Center)

"If lactating mothers find difficulty in performing exclusive breastfeeding, for example, her nipple is flat or she develop some disease, she will not intend to breastfeed exclusively" (Female, stakeholders of Regency's Health Service).

From the statement above, it can be interpreted that perceived behavioral control dimension suggests self confidence and exclusively breastfeeding ability, and individual's perceived easiness or difficulty of breastfeeding exclusively. It also shows whether or not there are necessary resource and opportunity, and lactating mothers have behavioral control and trust in controlling exclusive breastfeeding behavior. It indicates that individuals have ever performed a behavior, have facility and time to perform some behavior, and estimate their ability of performing behavior. Intention and perceived behavioral control are determinants of behavior. 
3.2.2.4 The Relationship Between Perceived Control Over Exclusive Breastfeeding and Exclusive Breastfeeding Behavior

The result of in-depth interview with some informants is presented below.

"Since I was pregnant, I have intended to breastfeed my baby exclusively, I have done so, and my baby has been 8 month old now, so I have given him supplement food" (Lactating mothers, 39 years, 8-month baby).

"In one case, a mother has flat nipple and she finds difficulty in breastfeeding exclusively, so that she does not do so" (Female, Nutrition Specialist of Public Health Center).

"Perceived behavioral control relates to 3 aspects: economy, education, and environment" (Male, Physician, Chairman of Public Health Center).

"Perceived behavioral control includes mothers' perception the benefit of breastfeeding. It will improve their exclusive breastfeeding behavior" (Male, stakeholders of Regency's Health Service).

"Resource and time available to perform exclusive breastfeeding supports exclusive breastfeeding behavior" (Female, a stakeholder of Regency's Health Service).

From the statement above, it can be interpreted that perceived behavioral control is defined as self-efficacy, a belief that lactating mothers have been experienced with performing exclusive breastfeeding behavior, resource and time to do so, and they can estimate their own ability of performing exclusive breastfeeding behavior; lactating mothers with self-confidence in breastfeeding will deal with breastfeeding problem more readily and attempt to breastfeed exclusively.

3.2.2.5 Exclusive Breastfeeding Intention and Exclusive Breastfeeding Behavior

The result of interview with some informants is presented below.

"I have breastfeed all of my children exclusively, this is my third child, and since I was pregnant I have intended to do so, and I trust that I can do it" (Lactating mother, 39 years, 8-month baby).

"If lactating mothers have exclusive breastfeeding intention, they will realize the intention into exclusive breastfeeding behavior" (Female, Coordinator Midwife, Public Health Center)

"If lactating mothers have exclusive breastfeeding intention, they will do anything to do so" (Female, Nutrition Division of Public Health Center)

"There has been an intention but it is defeated by time pressure. For example, a civil servant who should go to office at 07.00 a.m. will find difficulty to breastfeed exclusively" (Male, stakeholder of Regency's Health Office).

"I have intended to breastfeed exclusively, and my husband supports me, so that during furlough I pump my breast milk diligently" (Female, stakeholders of Regency's Health Office).

From the information above, it can be interpreted that exclusive breastfeeding dimension is a certainty about exclusive breastfeeding behavior practice; lactating mothers' tendency to perform exclusive breastfeeding. Intention serves as main determinant of behavior and direct antecedent of behavior. Intention captures motivation dimension related to behavior. Exclusive breastfeeding intention is an individual's perception on the performance of exclusive breastfeeding behavior; intention is determined by the extent to which individual has positive attitude to behavior and is supported by others affecting their life.

\subsubsection{Result of Focus Group Discussion}

The result of FGD with stakeholders of exclusive breastfeeding program in Public Health Center is cited as follows:

"Exclusive breastfeeding coverage is still low. For that reason, there should be an attempt of reinforcing lactating mothers' exclusive breastfeeding intention through motivation and education. If there is no intention, behavior will be weak and even pseudo; many factors affect intention including occupation, urban people assume that people including women - should work, as when she has no job, she will be underestimated; therefore women prefer working and limiting their opportunity of breastfeeding exclusively. Lactating mothers with strong perception, intention and behavioral control will stop their exclusive breastfeeding behavior when lactating room is not available, workplace is distance, and lactating furlough is inadequate. Intention is also affected by media and formula milk promotion. In rural area, there is a strong social norm including custom, pressure, paternalistic community, and parent and family's strong influence. What our ancestors did creates exclusive breastfeeding attitude. Originally, compulsion should be done; then voluntariness will be created, just like regulation that is compulsive in nature to create voluntariness. Attitude, subjective norm, and perceived behavioral control all relate 
to exclusive breastfeeding intention and behavior. Exclusive breastfeeding is performed more widely in rural areas due to its supporting norms, while in urban areas exclusive breastfeeding intention is affected by occupation and the availability of infrastructures such as lactation room".

The result of FGD with stakeholders of exclusive breastfeeding program in Health Service of Karanganyar Regency is cited as follows:

"In policy domain, exclusive breastfeeding becomes a problem due to the changing mindset - toward a modern life norm. For that reason, we take some attempt to change community's mindset and behavior. We develop policy related to exclusive breastfeeding behavior about comprehensive health development giving the element of community an opportunity of participating in health sector as the foundation of healthy regency. We can include it into strategic plan, codified into Regent's Regulation No.82 of 2015 governing mother's obligation during lactation period to breastfeed exclusively, and in 2016 we propose draft local regulation stating the attempt of improving mother and children's life quality into which exclusive breastfeeding and early breastfeeding initiation are included. Health promotion activity has been done, despite less optimal result. Documentation of Clean and Healthy Behavior (has been implemented annually, the result of which shows that in 2016 indicator of exclusive breastfeeding reaches $72.28 \%$ out of $75 \%$ targeted, but we only intervene mothers' knowledge improvement about exclusive breastfeeding. The implementation of exclusive breastfeeding program in Karanganyar Regency is conducted, among others, through holding pregnant woman class in all villages in agreed place, giving exclusive breastfeeding education in under-five age class and Integrated Service Post in all villages, and providing lactation room in offices and factories".

It can be interpreted that exclusive breastfeeding behavior builds on intention; for that reason exclusive breastfeeding intention should be reinforced through motivating and educating, but many factors attenuate the intention: occupation, media, formula milk promotion, and infrastructure availability. Value order (social norm) such as custom and regulation is environment's pressure to breastfeed exclusively. The implementation of exclusive breastfeeding should be supported with work leave adequacy, lactation room availability in all offices and factories. Attitude, subjective norm, and perceived behavioral control are all related to exclusive breastfeeding intention and behavior.

\subsubsection{Result of Document Review}

Considering on document review, exclusive breastfeeding in Karanganyar Regency is $61.1 \%$ in 2016, increasing from $58.1 \%$ in $2015,25.12 \%$ in $2014,14.93 \%$ in $2013,30.9 \%$ in 2012 , and $31.5 \%$ in 2011 . The number of under-five age children below red line is $413(0.8 \%)$, while there are $22(0.036 \%)$ malnutrition cases (Health Service of Karanganyar Regency, 2017).

\subsubsection{Field Observation Results}

Field observation was conducted in Public Health Center and Integrated Service Post during research process showing that averagely 2-3 lactating mothers bring their babies to Puskesmas out of 75 visits per day. Meanwhile, in Integrated Service Post, averagely 7-15 lactating mothers visit Posyandu per Integrated Service Post out of 75 visits per Integrated Service post.

\section{Discussion}

TPB predicts strongly exclusive breastfeeding intention and behavior. This finding supports the relationship between TPB constructs hypothesizing that exclusive breastfeeding intention is affected by attitude, subjective norm, and perceived control behavior in exclusive breastfeeding behavior. Generally, previous studies emphasizes on exclusive breastfeeding intention as main determinant of exclusive breastfeeding behavior model. Mothers' breastfeeding intention evidently affects exclusive breastfeeding duration significantly (Bai et al., 2010). Mothers' breastfeeding intention is related significantly to positive breastfeeding attitude, previous breastfeeding experience and supporting husband. These factors should be taken into account during planning the breastfeeding promoting program (Al-Akour et al., 2010).

TPB framework gives insight into the effect of breastfeeding intention on actual behavior and related determinant (Dodgson et al., 2003). TPB components are relevant to population, and the study exploring exclusive breastfeeding behavior domain can inform intervention intended to promote breastfeeding as social norm, and in turn improve breastfeeding attitude and exclusive breastfeeding behavior outcome (Lou et al., 2014). Understanding the determinant of exclusive breastfeeding behavior is the first step toward a successful intervention and policy development. The result of research shows that TPB provides a framework to explain main dimension of exclusive breastfeeding behavior (Hamade et al., 2013). This research confirms that TPB has a good predictive ability in explaining exclusive breastfeeding intention and behavior among populations. It is in line with 
Jamei et al.'s (2017) study concluding that TPB is an appropriate framework to identify factors related to exclusive breastfeeding behavior among nulliparas. Therefore, designing intervention based on TPB potentially improves exclusive breastfeeding practice. Through identifying the important determinant affecting exclusive breastfeeding behavior, appropriate intervention and education strategy can be designed to promote exclusive breastfeeding and to prevent early breastfeeding ceasing (Jamei et al., 2017).

Positive relationship between lactating mothers' attitude and exclusive breastfeeding intention found in this study is in line with previous studies' finding (Kools et al., 2005; Cernadas et al., 2003). Ismail et al. (2016) in their study found that expanded TPB theory has a good predictive ability in explaining exclusive breastfeeding and behavior. Woman's intention to practice exclusive breastfeeding can be improved by improving perceived behavioral control and attitude. Supporting postpartum women appropriately and giving them skill to deal with breastfeeding difficulty can improve their exclusive breastfeeding behavior (Ismail et al., 2016). Other studies identifies that significant broad support from others and lactating mothers' perceived behavioral control affect exclusive breastfeeding intention considerably (Kools et al., 2005; Swanson \& Power, 2005). Therefore, some attempts should be taken to create supporting environment in family and community to improve exclusive breastfeeding among lactating mothers in rural areas. This study found that the three constructs - attitude, subjective norm, and perceived behavioral control - relate significantly to breastfeeding intention (Al-Akour et al., 2010; Kools et al., 2005). Evidence shows that TPB variables (attitude, subjective norm, and perceived behavioral control) relate to breastfeeding outcome (intention and behavior), but this effect will be stronger for mothers with previous breastfeeding experience than for those breastfeeding for the first time (Bartle et al., 2017).

Ismail et al.'s (2014) study concluded that respondents agree to comply with four references from their mother, husband, nurse, and mother in law. Exclusive breastfeeding promotion should involve mother, husband, and mother in law. Nurse should give accurate and complete information related to breastfeeding practice. Encouraging lactating mothers to continue exclusive breastfeeding practice can improve exclusive breastfeeding intention and practice. Swanson \& Power (2005) in their study revealed that women's breastfeeding decision is affected by cultural norm and practice accepted and expected socially. Social norm or social effect may come from close family, neighbor, or relative. These people's belief becomes mothers' belief unintentionally. Swanson's finding is in line with current study finding that there a direct and significant relationship between subjective norm and exclusive breastfeeding intention. For that reason, exclusive breastfeeding promoting intervention should adopt a broad social approach in the future, to encourage positive norm for prospect mothers and fathers, family and parent. Donath \& Amir's (2003) study reported that breastfeeding initiation is closely related to breastfeeding intention. Knowledge, belief, and support are factors affecting exclusive breastfeeding intention. Meanwhile, general belief, breastfeeding stigma, support and influence from husband, mother, family member, and relative are factors affecting breastfeeding sustainability (Nuzrina et al., 2016).

Leshi et al. (2016) study gave information about knowledge, attitude and breastfeeding intention in Nigerian women. This study found that breastfeeding knowledge is relatively good, but positive attitude and breastfeeding intention are still inadequate. Therefore, the author recommended the improvement of young adult women's knowledge and attitude to exclusive breastfeeding, thereby improving the exclusive breastfeeding intention and the potential exclusive breastfeeding optimally. Intervention focuses on ensuring good breastfeeding knowledge and intention. Meanwhile, Pakpouret al. (2016) argued that intervention to improve knowledge, attitude, and perceived behavioral control on exclusive breastfeeding in young adult women with low social-economic status should be taken into account. The result of Nam Mi et al. (2015) study showed that the improvement of knowledge, attitude, and interest in breastfeeding is related to longer breastfeeding duration among adult women using internet as information source and communication tool concerning children. This finding suggests that targeting mothers with relatively low education level can be an effective strategy to encourage the successful breastfeeding practice in Korea.

Furthermore, Wan et al. (2015) shows five predictors of exclusive breastfeeding: breastfeeding knowledge, attitude, subjective norm, perceived behavioral control, and working status significantly predicting exclusive breastfeeding practice 4 months post-partum among Chinese women. Giles et al. (2014) study gave evidence to support TPB use in design and evaluation on school-based intervention to improve positive breastfeeding attitude in order to improve women's breastfeeding intention. Recalling the intention-behavior relationship likely attenuated over time and less durable effect of intervention, intervention can be repeated periodically and evaluated in long term to assess any potential change over times in adolescents' attitude to breastfeeding and perception on social effect, control, and self-efficacy in relation to breastfeeding.

Meanwhile, Hamade et al. (2013) study found that mothers' working status, breastfeeding intention and infant's 
birth age and physical health is related significantly to exclusive breastfeeding. This varying determinant determines ecological approach to breastfeeding promotion. Bartle et al. (2017) study concluded that experience with formula milk administration, representing social norm of baby feeding, evidently exerts negative effect either directly or indirectly through attitude and subjective norm on breastfeeding in 6 first weeks breastfeeding and experience mothers. Furthermore, formula milk administering attitude (weak positive breastfeeding attitude) and subjective norm are related to baby feeding intention and behavior affected more by common behavior in community (formula milk administration) than by personal attitude. Intervention to reduce formula milk administration exposure (by limiting advertisement) or protecting mothers from its impact enables more mothers to meet the target of exclusive breastfeeding.

Linares et al. (2014) reported that prenatal treatment offers a unique opportunity to improve breastfeeding intention that can improve exclusive breastfeeding in health-susceptible population. Wu et al. (2014) study shows that self-efficacy intervention is an effective to improve perceived behavioral control over breastfeeding, exclusiveness, and duration for primiparas. This finding indicates that intervention intended to improve perceived behavioral control has significant effect on the mothers' breastfeeding effectiveness and outcome. It reveals that perceived behavioral control over breastfeeding behavior can be modified. Health workers should give perceived behavioral control intervention to educate postpartum mothers to breastfeed. Breastfeeding education, according to TPB, delivered in the first grade of Senior High School effectively improves students' knowledge, attitude, and belief in breastfeeding and breastfeeding intention among adolescents in rural areas (Seidel et al., 2013).

Research limitation - This research studies determinant of exclusive breastfeeding intention and behavior only; a study on ecological, social-cultural determinant and education intervention is required to improve exclusive breastfeeding among lactating mothers. This study's findings likely exaggerate exclusive breastfeeding intention, thereby resulting in potential biased desire of community. Many more varying results can be obtained through broader respondent coverage.

\section{Conclusion}

Exclusive breastfeeding behavior model in Indonesian rural lactating mothers consists of attitude, subjective norm, perceived behavioral control, exclusive breastfeeding intention and behavior. Attitude, subjective norm, and perceived behavioral control are collectively related to exclusive breastfeeding behavior intention; intention and perceived behavioral control are direct determinants of exclusive breastfeeding behavior. Improving exclusive breastfeeding coverage can be done by helping improve positive attitude, change subjective norm to support exclusive breastfeeding, improve perceived behavioral control, and reinforcing exclusive breastfeeding intention. This finding will impact on better understanding on the importance of strengthening the lactating mothers' exclusive breastfeeding intention in Indonesian rural areas as an appropriate intervention strategy to achieve an optimum exclusive breastfeeding level. Giving educating intervention during lactating and even pregnancy period is beneficial to create positive attitude and empower mothers to achieve a belief in controlling exclusive breastfeeding behavior. As subjective norm affects breastfeeding behavior directly, physician, midwife, nurse and health worker's recommendation plays an important role in growing and strengthening mothers' intention to breastfeed exclusively. In addition, growing husband, mother in law, and other family members' awareness and care can play an effective role in improving exclusive breastfeeding behavior. Overall, TPB construction is recommended to be framework to apply education intervention to improve mothers' performance in exclusive breastfeeding behavior.

\section{Acknowledgements}

The authors thank to the Chairperson of Research and Public Service Institution of SebelasMaret University for funding this study in Mandatory scheme. We also thank Local Government of Karanganyar Regency, Central Java, Indonesia for permitting and facilitating this study.

\section{Competing Interests Statement}

The authors declare that there are no competing or potential conflicts of interest.

\section{References}

Ajzen, I. (2005). Attitudes, Personality and Behavior (2nd ed.). Maidenhead. England: Open University Press.

Ajzen, I. (2006). Perceived Behavioural Control, Self-efficacy, Locus of Control and the Theory of Planned $\begin{array}{lllll}\text { Behaviour. Journal of Applied Social Psychology, } & 32, & 1-20 .\end{array}$ https://doi.org/10.1111/j.1559-1816.2002.tb00236.x.

Ajzen, I. (2012). The theory of planned behavior. In P. Lange, A. Kruglanski, \& E.T. Higgins (Eds.), Handbook of 
theories of social psychology (pp. 438-459). London, UK: Sage.https://doi.org/10.4135/9781446249215.n22

Al-Akour, N. A., Khassawneh, M. Y., Khader, Y. S., Ababneh, A. A., \& Haddad, A. M. (2010). Factors affecting intention to breastfeed among Syrian and Jordanian mothers: a comparative cross-sectional study. International Breastfeeding Journal, 5(6), 1-8. https://doi.org/10.1186/1746-4358-5-6

Bai, Y., Middlestadt, S. E., Peng, C. Y. J., \& Fly, A. D. (2010). Predictors of continuation of exclusive breastfeeding for the first six months of life. Journal of Human Lactation, 26(1), 26-34. https://doi.org/10.1177/0890334409350168

Bartle, N. C., \& Harvey, K. (2017). Explaining infant feeding: The role of previous personal and vicarious experience on attitudes, subjective norms, self-efficacy, and breastfeeding outcomes. British Journal of Health Psychology, 22(4), 763-785. https://doi.org/10.1111/bjhp.12254

Cernadas, J. M., Noceda, G., Barreara, L., Martinez, A. M., \& Garsd, A. (2003). Maternal and perinatal factors influencing the duration of exclusive breastfeeding during the first 6 months of life. Journal of Human Lactation, 19(2), 136-144. https://doi.org/10.1177/0890334403253292

Dodgson, J.E., Henly, S.J., Duckett, L., \& Tarrant, M. (2003). Theory of planned behaviour-based models for breastfeeding duration among Hong Kong mothers. Nursing Research, 52(3), 148-158. https://doi.org/10.1097/00006199-200305000-00004

Donath, S., \& Amir, L. (2003). Relationship between prenatal feeding intention and initiation and duration of $\begin{array}{lllll}\text { breastfeeding: A } & \text { cohort } & \text { study. }\end{array}$ https://doi.org/10.1111/j.1651-2227.2003.tb00558.x

Fishbein, M., \& Ajzen, I. (2010). The reasoned action approach. In. Predicting and Changing Behavior: The Reasoned Action Approach (pp.21-23). New York, NY: Psychology Press.

Forster, D. A., McLachlan, H. L., \& Lumley, J. (2006). Factors associated with breastfeeding at six months postpartum in a group of Australian women. International Breastfeeding Journal, 1, 18. https://doi.org/10.1186/1746-4358-1-18

Giles, M., McClenahan, C., Armour, C., Millar, S., Rae, G., Mallett, J., \& Stewart-Knox, B. (2014). Evaluation of a theory of planned behavior-based breastfeeding intervention in Northern Irish Schools using a randomized cluster design. British Journal of Health Psychology, 19, 16-35.https://doi.org/10.1111/bjhp.12024

Hamade, H., Chaaya, M., Saliba, M., Chaaban, R., \& Osman, H. (2013). Determinants of exclusive breastfeeding in an urban population of primiparas in Lebanon: a cross-sectional study. BMC Public Health, 13, 702, 2-10 https://doi.org/10.1186/1471-2458-13-702

Health Service of Karanganyar Regency. (2017). Health Profile of Karanganyar Regency 2016. Karanganyar Central Java. www. karanganyar regency's.

Horta, B. L., Bahl, R., Martines, J. C., \&Victora, C. G. (2007). Evidence on the long-term effects of breastfeeding: systematic reviews and meta-analyses. Geneva: World Health Organization. Retrieved from http://www.who.int/child-adolescent-health.

Imdad, A., Yakoob, M. Y., \& Bhutta, Z. A. (2011). Effect of breastfeeding promotion interventions on breastfeeding rates with special focus on developing countries. BMC Public Health, 11(Suppl 3), 24-32.https://doi.org/10.1186/1471-2458-11-S3-S24

Ismail, T. A. T., Wan Muda, W. A. M., \& Bakar, M. I. (2014). Intention of pregnant women to exclusively breastfeed their infants: The role of beliefs in the theory of planned behavior. Journal of Child Health Care, 18(2), 123-132.https://doi.org/10.1177/1367493512473857

Ismail, T. A. T., Wan Muda, W. A. M., \& Bakar, M. I. (2016). The extended Theory of Planned Behavior in explaining exclusive breastfeeding intention and behavior among women in Kelantan, Malaysia.Nutrition Research and Practice, 10(1), 49-55. Retrieved from http://chc.sagepub.com/content/18/2/123.

Jamei, F., Ostovar, A., \& Javadzade, H. (2017). Predictors of Exclusive Breastfeeding among Nulliparous Iranian Mothers: Application of the Theory of Planned Behavior. Int $J$ Pediatr, 5(3), 4457-67. https://doi.org/10.22038/ijp.2016.20815.1748

Karanganyar Regency's Government. (2017). Profile of Karanganyar Regency in 2016. Retrieved from www. kabupatenkaranganyar.

Kavanagh, K. F., Lou, Z., Nicklas, J. C., Habibi, M. F., \& Murphy, L. T. (2012). Breastfeeding knowledge, 
attitudes, prior exposure, and intent among undergraduate students. J Hum Lact, 28(4), 556-64. https://doi.org/10.1177/0890334412446798

Kramer, M. S., \& Kakuma, R. (2002). The optimal duration of Exclusive Breastfeeding A Systematic Review. Department of Nutrition for Health and Development Department of Child and Adolescent Health and Development World Health Organization.

Kools, E. J., Thijs, C., \& de Vries, H. (2005). The behavioral determinants of breastfeeding in the Netherlands: predictors for the initiation of breast-feeding. Health Education and Behaviour, 32(6), 809-824. https://doi.org/10.1177/1090198105277327

Leshi, O., Samuel, F. O., \&Ajakaye, M. O. (2016). Breastfeeding Knowledge, Attitude and Intention among Female Young Adults in Ibadan, Nigeria. Open Journal of Nursing, 6(1), 11-23. https://doi.org/10.4236/ojn.2016.61002

Linares, A. M., Rayens, M. K., Gomez, M. L., Gokun, Y., \& Dignan, M. B. (2014). Intention to Breastfeed as a Predictor of Initiation of Exclusive Breastfeeding in Hispanic Women. J Immigrant Minority Health. Springer Science+Business Media New York.https://doi.org/10.1007/s10903-014-0049-0

Lou, Z., Zeng, G., Orme, J.G., Huang, L., Liu, F., Pang, X., \& Kavanagh, K. F. (2014). Breastfeeding Knowledge, Attitudes, and Intention in a Sample of Undergraduate Students in Mainland China. Journal of Human Lactation, 30(3), 331-339. https://doi.org/10.1177/0890334414526058

Miles, M. B., \& Huberman, A. M. (1994). Qualitative data analysis, an expanded sourcebook (2nd ed.). London: Sage Publications.

Nam Mi, K., Yoon Ji, C., Taisun, H., \& Jung Eun, L. (2015). Associations of Breastfeeding Knowledge, Attitude and Interest with Breastfeeding Duration: A Cross-sectional Web-based Study. J Korean AcadNurs, 45(3), 449- 458. https://doi.org/10.4040/jkan.2015.45.3.449

Nuzrina, R., Roshita, A., \& Basuki, D.N. (2016). Factors affecting breastfeeding intention and its continuation among urban mothers in West Jakarta: a follow-up qualitative study using critical point contact for breastfeeding. Asia Pac J Clin Nutr, 25(Suppl 1), S43-S51. https://doi.org/10.6133/apjen.122016.s10

Pakpour, A., Alijanzadeh, M., Pouresmaeil, M., Taherkhani, F., Mohammadgholiha, R., \& Jozi, N. (2016). Predictive Factors Associated with Breastfeeding Initiation and Duration Behaviors of 6-months Postpartum Mothers Referred to Health Centers in the City of Qazvin Based on Theory of Planned Behavior. Iran J Health Educ Health Promot, 4(1), 20-30. https://doi.org/10.18869/acadpub.ihepsaj.4.1.20

Republic of Indonesia's Health Ministry. (2017). General Secretariat. Indonesian Health Profile in 2016. Jakarta: Republic of Indonesia's Health Ministry.

Seidel, A. K., Schetzina, K. E., Freeman, S. C., Coulter, M. M., \&Colgrove, N. J. (2013). Comparison of Breast-feeding Knowledge, Attitudes, and Beliefs Before and After Educational Intervention for Rural Appalachian High School Students. The Southern Medical Association, 106(3), 224-229. https://doi.org/10.1097/SMJ.0b013e3182882b8f

Shi, L., Zhang, J., Wang, Y., \& Guyer, B. (2008). Breastfeeding in rural China: association between knowledge, attitudes, and practices. Journal of Human Lactation, 24(4), 377-385. https://doi.org/10.1177/0890334408319157

Swanson, V., \& Power, K. G. (2005). Initiation and continuation of breastfeeding: theory of planned behavior. Journal of Advanced Nursing, 50(3), 272-282. https://doi.org/10.1111/j.1365-2648.2005.03390.x

Wan, H., Tiansawad, S., Yimyam, S., \& Sriaporn, P. (2015). Factors Predicting Exclusive Breastfeeding among The First Time Chinese Mothers. Pacific Rim Int J Nurs Res, 19(1), 32-44. Retrieved from https://www.researchgate.net/publication/272295760_Factors_Predicting_Exclusive_Breastfeeding_among _The_First_Time_Chinese_Mothers

World Health Organization, United Nations Children's Fund. (2003). Global strategy for infant and young child feeding. Geneva: World Health Organization. Retrieved from http://apps.who.int/iris/bitstream/10665/42590/1/ 9241562218.pdf.

World Health Organization [WHO]. (2014). Global targets 2025. To improve maternal, infant and young child nutrition. Retrieved from www.who.int/nutrition/topics/nutrition_globaltargets2025/en/

Wu, D. S., Hu, J., McCoy, T. P., \& Efird, J. T. (2014). The effects of a breastfeeding self-efficacy intervention on 
short-term breastfeeding outcomes among primiparous mothers in Wuhan, China. J Adv Nurs., 70(8), 1867-79. https://doi.org/10.1111/jan.12349

\section{Copyrights}

Copyright for this article is retained by the author(s), with first publication rights granted to the journal.

This is an open-access article distributed under the terms and conditions of the Creative Commons Attribution license (http://creativecommons.org/licenses/by/4.0/). 